\title{
Antimicrobial Resistance in the Farm-To-Plate Continuum: More Than a Food Safety Issue
}

Luria Leslie Founou ${ }^{1,2,3 *}$, Raspail Carrel Founou ${ }^{2,4}$, Sabiha Yusuf Essack²

${ }^{1}$ Department of Food Safety and Environmental Microbiology, Centre of Expertise and Biological Diagnostic of Cameroon, Yaoundé, Cameroon

${ }^{2}$ Antimicrobial Research Unit, College of Health Sciences, University of KwaZulu-Natal, Durban, South Africa

${ }^{3}$ Department of Biomedical Sciences, Higher Institute of Medical Technology, Yaounde, Cameroon

${ }^{4}$ Department of Clinical Microbiology, Centre of Expertise and Biological Diagnostic of Cameroon, Yaoundé, Cameroon

${ }^{5}$ Department of Medical Microbiology, Faculty of Medicine and Pharmaceutical Sciences, University of Dschang, Dschang, Cameroon

Running title: Antimicrobial Resistance and food safety

Keywords: Antimicrobial resistance, Foodborne illness, Food Safety, Food Security, Sustainable Development

Words count: 9408

Number of Figures: 02

Number of Tables: 01

\section{*Corresponding author:}

Luria Leslie Founou

Centre of Expertise and Biological Diagnostic of Cameroon

Yaounde, 8242

Cameroon

Email: luriafounou@gmail.com 


\begin{abstract}
Antimicrobial resistance (AMR) threatens to reverse the essential benefits of antibiotics not only in humans, where decades of advancements in healthcare outcomes are endangered but also in the food production industry. The emergence of AMR in the pre- and post-harvest systems presents a serious risk of contamination or infection directly by antibiotic-resistant bacteria (ARB) and genes (ARGs) for farmers, agricultural practitioners, abattoir workers, food handlers and their associated contacts as well as consumers at the end of the food chain. Any breach in the food safety barrier leading to the emergence and spread of ARB and ARGs has severe multi-sectorial implications and threatens to reverse decades of human and animal health improvements globally. As the world moves towards Sustainable Development Goals (SDGs), food safety is a critical element to improve and strengthen global health, security and ensure sustainable development. This paper presents the challenge of AMR through the lens of food safety, by highlighting its multi-sectoral and multi-dimensional implications not only the SDG on food safety but also on food security, public health, animal health and welfare, the environment and climate and socio-economic development.
\end{abstract}




\section{Introduction}

Generally, agriculture is the group of technical processes and works in natural fields including terrestrial and aquatic environments, which allow the production of food products. It encompasses several activities including crop production, livestock breeding, aquaculture, fishing and hunting, all of which are associated with the farm-to-plate continuum. The availability and use of antimicrobials, especially antibiotics, in the food production industry (viz. terrestrial and aquatic animal and crop production) is indispensable to maintain animal health and welfare, sustain productivity, contribute to food safety and security, and for the protection of livelihoods (FAO, 2015). However, the increasing worldwide concerns related to antimicrobial resistance (AMR) threatens to reverse essential benefits of antibiotics not only in humans, where decades of advancements in healthcare outcomes are endangered but also in the food production industry (FAO, 2015).

AMR is a general term, that encompasses the resistance of bacteria, fungi, parasites, viruses to antimicrobials normally active against them, whereas, antibiotic resistance (ABR) is a more specific concept of bacterial resistance to antibiotic substances. For the purpose of this paper, the commonly used term antimicrobial resistance is retained, albeit the emphasis on antibiotic resistance. As an ancient and natural evolutionary process occurring whenever antimicrobial substances including antibiotics are used (Holmes et al., 2016), the rate of AMR emergence and spread has far outstripped progress in the development of new and effective antimicrobial drugs, leading the world towards a post-antibiotic era devoid of these life-saving substances (FAO, 2015). Although antibiotic use in human health has initially been established as the most important risk factor for the emergence and spread of AMR, the concern has been exacerbated due to the extensive use of antimicrobial drugs in the food animal production (Marshall and Levy, 2011; Landers et al., 2012; Chang et al., 2015; FAO, 2015; O'Neill, 2015; Founou et al., 2016). It is now widely acknowledged that increased AMR in bacteria affecting humans and animals is also influenced by the extensive usage of antimicrobials in animal production for a variety of purposes, including therapeutic and non-therapeutic uses as metaphylactics, prophylactics, and growthpromoters (FAO, 2015, 2016; O'Neill, 2016).

Emergence and spread of antibiotic-resistant bacteria (ARB) and antibiotic resistant genes (ARGs) in the farm-to-plate continuum (viz. from the farm to the end consumer) via direct and indirect contact has health and socio-economic repercussions globally. Direct contact, that occurs through immediate exposure of humans with infected or colonized food animals and their biological substances, enhances the rapid and easy dissemination of ARB and ARGs from host-to-host. The human population may also be exposed indirectly to ARB and ARGs via contact with or consumption of contaminated food products (Marshall and Levy, 2011; Founou et al., 2016). This indirect transmission has been associated with several foodborne illnesses outbreaks globally and is often considered more dangerous as it indicates the transfer or spread of AMR at each step in the continuum (WHO, 2015; EFSA and ECDC, 2016). Direct and indirect transmission of ARB and ARGs in the food chain increase the likelihood of their entrance and spread into communities and hospitals where substantial exchanges are possible, potentially jeopardizing healthcare systems (Marshall and Levy, 2011; Woolhouse et al., 2015; Founou et al., 2016). Moreover, with the globalisation of trade in animals and food products as well as international travel, there are no species, ecological nor geographical boundaries to contain AMR. Resistance emerging in one geographical location or bacterial species can easily spread or spill-over into several bacteria at each stage in the farm-to-plate continuum and similarly affect all countries, regardless of the 
income level (Founou et al., 2016; Holmes et al., 2016). AMR is thus a quintessential One Health issue requiring global solutions (Laxminarayan et al., 2013; FAO, 2015; WHO, 2015; Årdal C et al., 2016; Robinson et al., 2016).

Determining the relative implications of AMR emergence and spread in food animal production is a significant challenge given the interconnectedness and interdependence of epidemiological pathways between animals, humans and the environment (FAO, 2016). The United Nations (UN), The World Health Organization (WHO) (2015), The United Nations Food and Agriculture Organization (FAO) (2015), the World Organization for Animal Health (OIE) (2016), the World Bank (2016), the World Economic Forum (2013), and several other international organizations recognized AMR as a serious public health threat and global priority (World Economic Forum, 2013; WHO, 2015; FAO, 2015; OIE, 2016; World Bank, 2016; UN, 2017). As the world is moving towards the post-Millennium Development to Sustainable Development Goals (SDGs) (Sachs, 2012; UN, 2015), food safety is a critical element to improve and strengthen global health, security and ensure sustainable development (WHO, 2013, 2015a). This paper presents the challenge of AMR through the lens of food safety. First, it highlights foodborne illness as serious food safety issue; second, it underlines the multi-sectorial and multi-dimensional implications of the emergence and spread of AMR in the farm-to-plate continuum on the SDGs of food security, public health, animal health and welfare, the environment and climate, and socio-economic development; and finally, it suggests a global strategy to ensure food safety along with sustainable development.

\section{Foodborne illness as an important food safety issue}

Food safety is an area of global public health priority and a vital element to achieving several SDGs such as those pertaining to poverty, hunger and promoting health and well-being. Food is considered unsafe when it is likely to physically harm the consumer as a result of damage, deterioration and presence of biological or chemical substances (Prabhakar et al., 2010). It can become unsafe at different stages in the farm-to-plate continuum, either during the production, distribution, retail/sale or preparation and consumption. Unsafe food can cause several health problems ranging from acute or chronic food poisoning or foodborne illnesses, reproductive and developmental concerns, to AMR, cancers and deaths (Mensah et al., 2014). Antimicrobial use at production level leads to food safety issues associated with the presence of antibiotic residues (Mensah et al., 2014), ARB (Chairat et al., 2015) and ARGs (Ben Sallem et al., 2014) in food animals and products, whereas the lack of adequate transportation and storage facilities as well as limited hygiene practices lead to breach of food safety and the deterioration of food integrity during the transport, storage and processing, respectively (Prabhakar et al., 2010).

Emergence of AMR in the pre- and post-harvest systems presents a serious risk of contamination or infection directly by ARB and ARGs for farmers, agricultural practitioners, abattoir workers, food handlers and their associated contacts as well as consumers at the end of the food chain (Prabhakar et al., 2010). Foodborne illnesses are amongst the main public health consequences associated with unsafe food and water, particularly in infants, young children, pregnant women, elderly and people who have weak immune systems and are at high risk of acquiring and dying from foodborne illnesses. Foodborne illness ranges from mild and self-limiting disease including diarrheal episodes, vomiting and nausea, to debilitating and life-threatening consequences such as neural and brain disorders, kidney and liver failures, disabilities, cancers and death (WHO, 2011, 2015 b,c). Undernourished infants and children are more prone to develop more severe forms that often lead to premature death (WHO, 2011, 2015b,c). 
According to the WHO, foodborne illness caused approximately 600 million of cases with 420,000 premature deaths in 2010 (Jaffe et al., 2019). The global burden of food safety issues associated with foodborne illnesses is unequally distributed and differs from geographical location, income levels, health care infrastructure, diets and local conditions. By undertaking a systematic review of literature, Ao et al. (2015), demonstrated that globally, around 3.4 million cases of invasive nonTyphoidal Salmonella (iNTS) infection occurred from January 1990 to December 2012, with 681 316 deaths reported (Ao et al., 2015). The study revealed that Africa had the highest incidence (227 cases per 100000 population) and number of cases (1.9 million cases) annually with infants, young children and young adults being the most affected (Ao et al., 2015). Similarly, in another systematic review, Majowicz et al. (2014) revealed that shiga toxin-producing Escherichia coli (STEC), was involved in 2.8 million acute illness every year with 3890 cases of haemolytic uremic syndrome (HUS), 270 cases of end-stage renal diseases (ESRD) and 230 deaths being reported from January 1990 to April 2012 in ten out of 14 World Health Organization (WHO) sub-regions (Majowicz et al., 2014).

More specifically, in South East Asia, about one million children under five years of age die prematurely every year, from diarrhoeal episodes due to consumption of contaminated food and water (Prabhakar et al., 2010; Jahan, 2012). Likewise, foodborne illnesses claim around 200000 deaths annually in Nigeria with 124400 being children under five years old (Ajayi and Salaudeen, 2014). A report from the Foodborne Diseases Active Surveillance Network (FoodNet) of CDC's Emerging Infections Program conducting active and population based-surveillance for laboratorydiagnosed infections revealed that over a three-year period (2015-2018), 25,606 cases of infection, 5,893 hospitalizations, and 120 deaths were caused by pathogens transmitted through food with the principal pathogens being Campylobacter spp. (19.5\%), followed by Salmonella spp. (18.3\%), and STEC (5.9\%)(Tack et al., 2019). The emergence of resistant foodborne illnesses will thus considerably increase morbidity and mortality around the world, albeit the problem will be more severe in developing countries where AMR in the food chain is already considerably neglected regardless of the high prevalence of $\mathrm{ARB}$ and $\mathrm{ARGs}$ reported in food animals and food products (Fortini et al., 2011; Klibi et al., 2013; Adelowo et al., 2014; Boonyasiri et al., 2014; Fashae and Hendriksen, 2014; Iweriebor et al., 2015), and due to poor food production processes, lack of basic amenities, limited food storage infrastructures, sub-optimal hygienic conditions, unsafe water used for cleaning and cooking, and poor food handling (WHO, 2011).

In spite of all these concerns, food safety is still a veiled and often unheeded problem worldwide. The World Health Organization (WHO) consequently devoted its 2015's World Health Day to food safety, under the theme "From Farm-to-Plate, Make Food Safe", to invigorate decisionmakers and all stakeholders to implement effective and efficient measures that will improve safety of food on farms, factories, slaughterhouses, supermarkets, street vendors and at kitchens (WHO, 2015b).

\section{Antimicrobial resistance in the farm-to-plate continuum at the edge of United Nations' Sustainable Development Goals}

Any breach in the food safety barrier leading to the emergence and spread of ARB and ARGs has multi-sectoral implications and threatens to reverse decades of human and animal health improvements globally. Food security, animal health and welfare, climate and environmental health as well as socio-economic development are likely to be impacted by the emergence of AMR in the farm-to-plate continuum (Figure 1). 

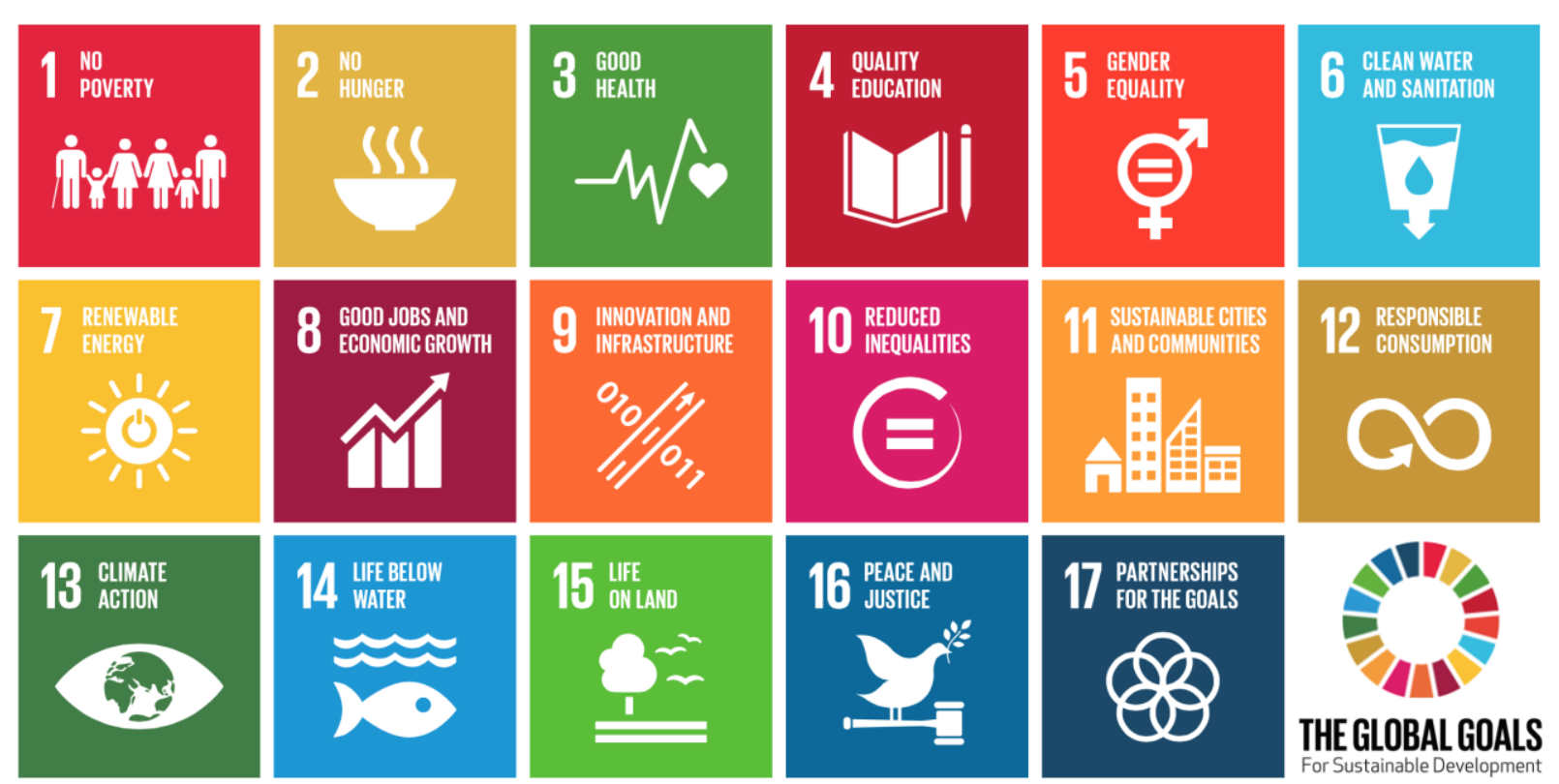

Figure 1. Chart of United Nations' Sustainable Development Goals

\section{Food security implications}

Food security is achieved "when all people, at all times, have physical and economic access to sufficient, safe and nutritious food that meets their dietary needs and food preferences for an active and healthy life" (FAO, 1996). Globally, food animals are significant sources of food, and the food production industry is an important contributor to the world economy (Smith et al., 2013; Tilman et al., 2011). Meat, milk and eggs are the major commodities produced from classical food animals such as cattle, buffaloes, pigs, poultry, sheep and goats, whereas in aquaculture, fish, crustaceans and molluscs are the foremost (FAO, 2013; Smith et al., 2013). The annual consumption of meat is around $80 \mathrm{~kg} /$ person in high-resource countries whilst it is about $10 \mathrm{~kg} /$ person in low- and middle-income countries (LMICs) (FAO, 2013). In 2010, 296 million tonnes of meat were produced worldwide, with $37 \%$ being pig meat, $33 \%$ poultry meat, $23 \%$ beef or buffalo meat and $5 \%$ goat or sheep meat (FAO, 2013). The same year, 69 million and more than 700 million tonnes of eggs and milk were produced, respectively; and aquaculture contributed with approximately 60 million tonnes of fish (FAO, 2013). The UN SDG 2 promotes end of hunger, achievement of food security, improved diet and sustainable agriculture by 2030 (UN, 2015).

However, nowadays, 700 million people living in rural areas are still living under extreme conditions of poverty. Approximately one-third of food produced is wasted or lost, leading to unnecessary pressure on Earth's resource and losses for agricultural practitioners (FAO, 2017), while around two billion people suffer from micronutrient deficiencies and 800 million are chronically hungry worldwide (FAO, 2017). The situation is likely to worsened propelled by the 2.3 billion persons increase in global population during the next 35 years. Indeed, according to the UN Department of Economic and Social Affairs (DESA) report (2015) the current global population of 7.3 billion is estimated to reach 8.5 billion in 2030, 9.7 and 11.2 billion by 2050 and 2100 respectively (UN DESA, 2015). This drives the world towards a three-fold challenge, (i) to match this unprecedented demand on animal and crop proteins from a bigger and more affluent population to its supply, (ii) do so in ways that are environmentally and socially sustainable, and (iii) ensure that the world's poorer people are continually food secure (Godfray et al., 2010). 
When food supplies become insecure, people lean towards less healthy diets and consume more unsafe food containing chemical and microbiological hazards and posing health risks (WHO, 2015) as food safety and security share a fundamental basis and are inextricably connected to one to another with feedback effects (FAO, 1996a,b, 2014). Van Boeckel et al. (2015) reported that changes from extensive farming systems towards large-scale intensive and industrialized production will be observed, with evident upsurge of negative conditions such as overcrowding, intensive human contacts with animals and environment, as well as considerable antimicrobial use in the food production industry that will lead to increased AMR in agriculture, and thereby in the farm-to-plate continuum (Van Boeckel et al., 2015). Unsafe food due to the emergence and spread of ARB and/or ARGs in food animals and products leads to a vicious cycle of worsening health including malnutrition and foodborne illnesses, that endangers the nutritional status of most vulnerable as well as the achievement of global food security as it may lead to chronic or transitory food insecurity across the world (FAO, 1996a,b; WHO, 2013, 2015).

In fact, the global spread of ARB and/or ARGs in the farm-to-plate continuum may cause price instability viz. increase of food costs (Godfray et al., 2010; FAO, 2015), as well as devastation of whole herds or flocks when resistant outbreaks will occur in several production systems (Bengtsson and Greko, 2014). It will thereby lessen access to safe food to poorer people and significantly aggravate hunger (FAO, 2015). Hunger hotspots may also emerge particularly in developing nations due to extensive emergence and persistence of ARB and ARGs in food animals and products, and protract the crisis (Godfray et al., 2010; FAO, 2015). Half billion-people located in more than 20 countries are already affected by hunger and this could be aggravated by AMR (Godfray et al., 2010; FAO, 2015). This implies that the extensive use of antimicrobial medicines in farming practices will threaten the achievement of UN's SDG 2 of eliminating hunger in our lifetime by 2030. Similarly, it will impede the eradication of all forms of poverty (SDG 1), endanger the achievement of global well-being (SDG 3), and jeopardize sustainable consumption and production (SDG 12).

Building efficient, inclusive and resilient food systems is needed for effective management of food security (FAO, 2017), as any efforts addressing food security or sustainable consumption and production, will have an impact on food safety and vice-versa (Godfray et al., 2010). Development of sustainable food production systems where high productivity is not over-reliant on antibiotic use, is of crucial importance to double the quantity of animal and crop proteins and reach the SDG 2 (Godfray et al., 2010; FAO, 2014, 2015; UN, 2015; Jasovsky et al., 2016). The Rome Declaration on Nutrition (2014) and World Food Summit (2012) already recognized that food systems must contribute to address and prevent infectious diseases, and curb the worldwide dissemination of AMR (FAO, 2012, 2014). It endorsed a Framework for Action recommending actions on food safety and AMR to (i) raise awareness among all stakeholders on this threat, implement adequate and comprehensive measures for its containment, and (ii) develop and implement national guidelines on judicious use of antibiotics in food animals, in line with international standards of competent supranational organizations (FAO, 2014).

Achievement of global food security would thus require not only comprehensive sustainable consumption and production, but mainly, sustainable access to safe food worldwide, thereby confirming food safety as one of the key elements to achieve world's food security (FAO, 2014, 2015; Jasovsky et al., 2016). Implementation of appropriate policies and activities to fight AMR are further of crucial importance to ensure food security for current and future generations (O'Neill, 2015b; WHO, 2015; Årdal et al., 2016). Although, the FAO recently called for a One Health and 
food chain approach to respond to the increasing threat of resistance in the world's food production systems, eradicate hunger and rural poverty, considerable public health strategies and activities are still required to ensure consumers' health through food safety.

\section{Implications for animal health and welfare}

AMR crosses food safety and security to reach animal health and welfare. Several reports on the consequences of AMR emergence and spread in the food chain relate the danger of ARB and ARGs transmission to people, and thereby its potential public health implications (Bengtsson and Greko, 2014; FAO, 2016; OIE, 2016). However, the repercussions of AMR in animals are not merely limited to human health and it has been reported that the emergence of ARB and ARGs in the food chain, put animal health and welfare at high risk and will subsequently have reverse repercussions on human livelihoods and food security.

Antimicrobials are critical to treat (as with humans) and prevent diseases in animals and are essential tools in maintaining animal health and welfare (FAO, 2016; OIE, 2016). However, without, timely and responsible use of effective antimicrobials, a resistant infectious disease could rapidly spread on-farm with direct and indirect negative impacts on animal health and welfare, endanger health of herds/flocks and safety/security of food (FAO, 2016; OIE, 2016).

For instance, soft tissue and surgical site infections in animals could, if left untreated due to inefficiency of antimicrobials, be life-threatening or lead to euthanasia of infected animals for welfare reasons (Bengtsson and Greko, 2014). Enteric and respiratory diseases are among the most significant in several animal species such as pigs and poultry, and mastitis is frequent in animals reared for milk production, including cows, goats, sheep, and buffaloes (Bengtsson and Greko, 2014). These diseases are basically highly contagious and therefore, more problematic when associated with resistant bacteria in farming systems where animals are kept in large and overcrowded groups, as they will cause drug-resistant infections of whole herds/flocks and thereby result in suffering of the animals (Bengtsson and Greko, 2014). To alleviate their implications, antimicrobials are used therapeutically for the treatment of sick animals, thereby prevent suffering and, as such, contributes to the welfare of animals, food safety and security, and productivity (FAO, 2016; OIE, 2016). This aspect, has yet received minimal or no scientific attention and, unlike in humans where the WHO published a global report on AMR (WHO, 2014), the worldwide burden of resistance on animal health is unknown and no report from the OIE mentioned it (Bengtsson and Greko, 2014).

Concerns for animal welfare arise with the routine growth promotion and prophylactic use of antimicrobial drugs. In fact, intensive farming across the world generally relies on prophylactic and growth-promotion use of antimicrobials to compensate for inherently low-welfare environments. In these systems, animals are reared in crowded and confined conditions resulting into compromised immune systems and favouring rapid spread of disease. Antimicrobials are then used prophylactically in order to anticipate outbreak of diseases in the herds/flocks (O'Neill, 2015; FAO, 2016). Although, at short-term the direct impact of prophylactic antimicrobial use on animal welfare might be positive as it prevents animals of falling sick, its indirect implications enable persistence of low-welfare environments that favours AMR spread (Bengtsson and Greko, 2014). Similarly, the use of antimicrobials for growth promotion pushes food animals towards their metabolic and physiological limits with several negative impacts on their welfare and making them more prone to (resistant) infectious diseases (Bengtsson and Greko, 2014; FAO, 2015, 2016). Reliance on regular and prolonged sub-lethal use of antimicrobials lead to ideal conditions for emergence and spread of ARB and ARGs (FAO, 2016). Improving animal welfare and health is 
therefore considered as an essential element of policies to ensure food safety, food security and public health.

The main way to minimize the levels of antimicrobial use in animals is to prevent infections and ensure good animal care, as on-farm activities directly affect the level of medications required. The key elements are biosecurity measures (good agricultural and good hygiene practices) and immunization that prevent the emergence and transmission of infectious diseases, ARB and ARGs, along with commercial incentives and disincentives, and, a legal framework regulating antibiotic use in animal sector. Experiences of some countries such as Denmark (DANMAP, 2014), Sweden, Norway (NORM and NORM-VET, 2015) and the Netherlands confirm that antimicrobial use in animals can be substituted by alternative measures including vaccines, good husbandry practices and biosecurity measures, without disruption of the productivity. This does not mean that antimicrobials should not be used at all, but rather, that it is crucial to maintain antimicrobial effectiveness for treating really sick animals, thereby reducing suffering, ensuring good welfare and top-class food safety for the consumers.

Also, given the fact that AMR has reduced the therapeutic arsenal for several animal diseases some antibiotics are no longer proposed as first-line drug and there are only few alternatives remaining for their management due to the widespread resistance. Penicillin for instance, that has been used for the treatment of mastitis caused by $S$. aureus in cattle since 1950s, is currently not an empirical first choice for this condition. Emergence of penicillin and tetracycline resistance in Mannheimia haemolytica (M. haemolytica) and Pasteurella multocida (P. multocida) responsible of pneumonia in calves make it difficult to use these drugs as first-line treatment in some part of the world (Bengtsson and Greko, 2014). Similarly, resistance in E. coli causing enteritis in young pigs has worldwide ousted trimethoprim-sulfamethoxazole as appropriate first therapeutic option (Bengtsson and Greko, 2014; Iweriebor et al., 2015).

Swine dysentery caused by the spirochete Brachyspira hyodysenteriae (B. hyodysenteriae) is a serious enteric infection for suckling pigs, that usually affects a large proportion of animals within a herd and persists with recurring outbreaks causing animal suffering and economic losses attributed to mortality, limited feed conversion, and retarded growth (Bengtsson and Greko, 2014). Resistance to antimicrobials previously used in the management of swine dysentery, including tylosin and lincomycin, is actually widespread, and nowadays, pleuromutilins are recommended. However, resistance to pleuromutilins has also been detected, making the management of swine dysentery difficult with serious constraints on the production of the farm where outbreaks of resistant B. hyodysenteriae emerge (Bengtsson and Greko, 2014).

The MRSA clonal complex (CC) 398 emerged in the last decade in pigs, and asymptomatically colonized various food animals. It has now been detected in milk and associated with mastitis in dairy cows with concomitant resistance to several antibiotics including tetracycline, gentamicin, trimethoprim-sulfamethoxazole and erythromycin (Weese, 2010). This implies that should MRSA strains become more prevalent in mastitis for instance, there will have limited or no antimicrobials available for its management (Bengtsson and Greko, 2014). Although such scenarios could certainly being managed in single herds through depopulation, cleaning and subsequent restocking under biosecurity measures, emergence and spread of multi-resistance in endemic bacteria such as $M$. haemolytica and B. hyodysenteriae, in indicator like E. coli and Enterococcus spp., and emerging pathogens such as MRSA CC 398, would have serious implications for productivity (especially in large-scale intensive production systems), food security and safety regardless of country-income, thereby threatening achievement of SDGs 1, 2, 3 and 12 (UN, 2015; Figure 2). Preserving the effectiveness of the current therapeutic arsenal is therefore crucial to ensure our 
ability to alleviate the threat posed by ARB and ARGs for animal health and welfare, as well as public health.

\section{Public health implications}

Antibiotics are essential health system resources whose future is currently endangered, requiring substantial efforts to ensure their effectiveness across all relevant sectors in general, and within the human health sector in particular (Tomson and Vlad, 2014; Ardal et al., 2016; Founou et al., 2016). The current widespread use of antibiotics in food animals raises ethical dilemmas and public health threats that cannot be managed in isolation, exclusively within health systems or even merely within the animal health sector (Tomson and Vlad, 2014; Årdal et al., 2016). In fact, antibiotics of a particular family tend to have similar physiochemical structures, modes of action and ranges of effectiveness, and therefore, bacteria expressing a resistance mechanism to one antimicrobial drug are more prone to extend resistance to another related compound. The implications of antimicrobial use in animal husbandry, aquaculture, horticulture and crop production on human health occur because similar or identical antimicrobials are used for several of these on-farm activities and in human health. Several reports have established a clear link between antimicrobial use in food animals and resistance in humans worldwide (Armand-Lefevre et al., 2005; van Loo et al., 2007; Leverstein-van Hall et al., 2011; Kluytmans et al., 2013). More specifically, it has been shown that food animals are the foremost source of AMR for some major human infections such as fluoroquinolone resistant Salmonella spp. and macrolide resistant Campylobacter spp. (Aidara-Kane et al., 2013), while there is strong evidence that they are involved in other infectious diseases caused by extended spectrum beta-lactamase (ESBL) producing-E. coli (Dahms et al., 2015; Dohmen et al., 2015; Denkel et al., 2016) and vancomycin resistant Enterococcus spp. (VRE) in humans (Swartz, 2002; Newell et al., 2010; Aidara-Kane et al., 2013; WHO, 2015c). The spread of MRSA CC 398 from animals to humans (exposed or not) via the food chain is the more tangible and recent evidence of zoonotic transmission of ARB in the farm-to-plate continuum, with reports from various countries (Voss et al., 2005; Armand-Lefevre et al., 2005; van Loo et al., 2007; Weese, 2010; Ward et al., 2014; Crombé et al., 2013).

Upon their emergence on farm, resistant bacteria from food animals may move from the farm to the plate via uncooked meat, milk, eggs, fish, shellfish and vegetables (Acar and Moulin, 2006; WHO, 2011). These bacteria could also pose public health problems to the consumer and cause foodborne illnesses due to food contamination occurring during the storage and cooking (WHO, 2011; Tomson and Vlad, 2014). Resistant shiga-toxin and entero-hemorrhagic producing E. coli, especially serogroups O157, O26, O91, O103, O111, O128 and O145, were for instance associated with severe foodborne gastro-enteritis across the world (Ojo et al., 2010; Olatoye, 2010).

Despite foodborne intestinal diseases due to E. coli, extra-intestinal illness associated with animaloriginating resistant bacteria is recently gaining considerable attention, with foodborne urinary tract infections representing the major paradigm shift in the understanding of these illnesses (Nordstrom et al., 2013; Singer, 2015). ARB from contaminated food products can transiently colonize the human gastro-intestinal tract that becomes a reservoir for subsequent infection (Carlet, 2012; Nordstrom et al., 2013; Rolain, 2013). Similar genetic fingerprints have been detected in geographically and temporally matched urinary tract infection (UTI) cases and E. coli from food. Specifically, in a case-control study assessing if the dietary habits of women were associated with multi-drug resistant UTIs, Manges et al., (2007) reported that women with multi-drug resistant UTIs were 3.7 times more likely to have frequently consume chicken whereas those with ampicillin or cephalosporin-resistant infections were 3.2 times more likely to report pork consumption (Manges et al., 2007). Likewise, Jakobsen et al., (2010) revealed that foodborne $E$. 
coli were not only genetically associated with UTIs in humans, but were also responsible of UTIs in vivo, with 13 foodborne phylogroup B2 of E. coli strains causing UTIs and pyelonephritis in a murine UTI model (Jakobsen et al., 2010).

Altogether, the emergence and spread of ARB and ARGs in the farm-to-plate continuum will likely hinder the success of infection and prevention control (IPC) measures and antimicrobial stewardship programs (ASP) implemented in communities and hospitals (Jasovsky et al., 2016; EFSA and ECDC, 2016, 2015; Roess et al., 2015; Ewers et al., 2012; Wooldridge, 2012; Weese, 2010). The breach in the food safety barrier due to resistant bacteria of animal origin threatens in parallel, health policies implemented to contain sustainably non-communicable diseases (NCDs) including diabetes mellitus, cardio-vascular, pulmonary and heart diseases, and communicable diseases such as HIV-AIDS, tuberculosis, malaria as immune-compromised patients suffering from these pathologies will be most affected (Jasovsky et al., 2016; Tomson and Vlad, 2014). As consequences of these and other likely damaging effects of the emergence and spread of AMR in the farm-to-plate continuum, the SDG 1 and 3 of ending poverty and ensuring healthy lives and promoting well-being would be difficult to achieve without effective antibiotics (Ardal et al., 2016; Jasovsky et al., 2016).

Effective containment of AMR within the healthcare system should therefore consider not only individuals, households, healthcare facilities and communities, but also, different pathways and drivers of AMR in the whole farm-to-plate continuum, within the One Health dynamics locally, regionally, nationally and globally (Tomson and Vlad, 2014). Thus, albeit several actions could be taken independently at sectoral and national levels, they will be more effective if coordinated worldwide across all relevant sectors and stakeholders (Laxminarayan et al., 2013; WHO, 2015; Ardal et al., 2016; Laxminarayan et al., 2016).

\section{Implications for socio-economic development}

In its 2013's annual report on global risks, the World Economic Forum concluded that "arguably the greatest risk ... to human health comes in the form of antibiotic-resistant bacteria. We live in a bacterial world where we will never be able to stay ahead of the mutation curve. A test of our resilience is how far behind the curve we allow ourselves to fall." (World Economic Forum, 2013; Spellberg et al., 2013). This has been confirmed by the AMR review which stated that a cumulative global economy loss of 100 trillion US \$ over the 35 next years will be attributable to AMR if considerable efforts are not sustainably implemented (O'Neill, 2015, 2016). In addition, the World Bank estimated that the annual cost of AMR could be as high as those of the 2008's global financial crisis and that low-and-middle-income countries (LMICs) would be most affected with the largest economic shortfalls in economic growth (World Bank, 2016). In fact, LMICs are estimated to face a total productivity loss of around US $\$ 95$ billion yearly owing to unsafe food with the cost of treating foodborne illnesses being projected at US\$ 15 billion (Jaffe et al., 2019). The total productivity loss associated with foodborne disease in low- and middle-income countries is estimated to cost US\$95.2 billion per year, and the annual cost of treating foodborne illnesses is estimated at US\$ 15 billion. Although difficult to quantify, other costs, include company sales and losses of farm, foregone trade income, the health repercussions of consumer avoidance, and the environmental burden of food waste. The majority of the health and economic burden could be avoidable through simple preventive measures, behavioural changes and investments adopted in the farm-to-plate continuum (Jaffe et al., 2019).

The financial consequences of AMR in the farm-to-plate continuum are basically the same as with human and veterinary health. Loss of antimicrobial effectiveness for infectious disease treatments due to AMR will cause suffering of the affected individual, whether it is an animal or a human 
being. Bacterial resistance to antimicrobials leads to high costs to individuals, households, hospitals, and societies, due to the necessity to use more expensive and toxic preparations as second or last line treatment, additional diagnostic tests and increase in hospital length of stay, as well as longer sick leave, and possibly, premature death (Ardal et al., 2016; Laxminarayan et al., 2013; RE-Act, 2016). However, in the food production industry, it is a normal procedure, to kill animals when treatment costs go beyond economic benefits. The inability to treat resistant infectious disease together with suffering and welfare problems for the animals, due to the loss of potent antimicrobials will thus in turn lead to loss of income for the farmer. Furthermore, financial losses that will occur due to higher mortality directly associated with resistant infections, and indirectly through reduced feed conversion, decreased growth and production, as well as premature culling of dairy cows and breeding animals, will result in higher costs of commodities derived from animal food production and ultimately for the end consumer (Bengtsson and Greko, 2014). AMR therefore negatively impacts agricultural practitioners and food production industry, as the absence of effective antibiotics to treat sick animals will irreversibly damage food productivity, leads to loss in consumers' confidence in the products, thereby reducing benefits (FAO, 2015, 2016, 2017).

In the lens of the consumer, substantial medical expenses, ill health, together with absenteeism at work and school that is prejudicial for the society will also be attributed to resistant foodborne infections (Padungtod et al., 2008; Prabhakar et al., 2010; Newell et al., 2010; Jahan, 2012; de Balogh et al., 2013). US National data of seven foodborne pathogens reported losses between 5.6 to 9.4 billion US \$ in absence at work and medical expenses whereas in the European Union, annual health care costs attributed to Salmonella infection alone were estimated at 3 billion $€$. The cost of 11500 daily cases of foodborne infections was estimated at 2.6 billion AU $\$$ annually in Australia. Based on 2011 CDC data, Scharff (2012) estimated at 1626 US \$ and 77.7 billion US $\$$ the average cost per case and annual cost of foodborne illness, respectively (Scharff, 2012). Yet, an even larger economic burden lies in the future and will more severely affect next generations, as the repercussions of current use (and misuse) of antimicrobials in terrestrial and aquatic food animals, crops, as well as complacency in the containment of AMR through the farm-to-plate continuum could lead to the loss of all the advances that led to modern medical care. Basic and sophisticated surgical procedures such as caesarean sections, knee or hip replacement, cancer chemotherapy might be impossible to envisage, resulting into tremendous economic and human costs for the world (World Economic Forum, 2013; RE-Act, 2016; World Bank, 2016).

At national level, lack of effective antimicrobials will also lead to financial losses attributed to reduced productivity of animals, losses of effective therapeutic options in human healthcare, that are subsequently associated with losses of productivity, societal costs and finally a drain of national and global economies (Bengtsson and Greko, 2014; Jasovsky et al., 2016). Consequences related to food contamination will drain the national economy as country's economic losses associated with resistant foodborne infections will range from increase of national medical expenses, outbreak investigations and food recalls. In 2011, an outbreak due to enterohaemorrhagic E. coli and linked with contaminated fenugreek sprouts emerged in Germany and spread in height countries in Europe and North America, with 53 deaths reported. This outbreak caused 1.3 billion US \$ losses for German farmers and industries and up to 236 million US \$ in emergency aid payments to 22 European Union member states (WHO, 2015a). The same year, an outbreak linked to a strain of Salmonella resistant to four antibiotics and originating from ground turkey caused 136 cases with one death and recalling of 36 million pounds of ground turkey in US (Tomson and Vlad, 2014). 
The 2016's World Bank report revealed that output and trade in food animals and products are especially vulnerable to AMR effects not merely because of reduced productivity associated with resistant infections, but also due to international trade disruption in the wake of disease outbreaks (World Bank, 2016). In fact, whether based on risk analysis or due to fear, import restrictions will be implemented and output in the food production industry will be further reduced. The report estimated that decline in global food production could range between 2.6-7.5\% of food products and LMICs will be the most affected with $11 \%$ loss in a simulation of worst AMR impact scenario (World Bank, 2016). This suggests that if nothing is done to significantly address this threat, the socio-economic development of several countries, particularly those in the developing world that relies mainly on agriculture and food production, will be seriously impeded, along with the achievement of some world's SDGs (Laxminarayan et al., 2013; Årdal et al., 2016; Jasovsky et al., 2016a; O'Neill, 2016). For instance, SDG 1 of eradicating poverty by 2030 would be difficult to reach as the number of poor people will be 8 million in an optimistic and up to 24 million in a pessimistic scenario, and the majority of these increases will occur in LMICs (World Bank, 2016). To a further extent, elimination of hunger, achievement of well-being for all, ensuring equitable education, sustainable management of water and sanitation for all as well as sustainable economic growth, and sustainable consumption promoted under SDGs 2, 3, 4, 6, 8 and 12 (Figure 2), respectively, may likely not be accomplished by the same period.

This makes AMR in the farm-to-plate continuum a critical, complex and global development concern. As a multifaceted food-related issue, success in dealing with AMR in the farm-to-plate continuum will only be achieved through a collaborative and holistic One Health approach that considers not only the problem itself, but also all upstream and downstream factors associated with it.

\section{Implications for environmental health and climate change Environmental health}

The use of antibiotics for prevention, treatment and growth promotion purposes in animal husbandry and fish farming as well as in crop production enable their release in natural ecosystems (Martinez, 2009; Berendonk et al., 2015; Thanner et al., 2016). A large fraction (30-90\%) of these antibiotics are not transformed into inactive compounds, retain their biologically active form and enter either to waste water treatment plants (WWTPs) or directly into groundwater or soils with one of three fates: (i) absorption to sewage sludge (Li and Zhang, 2010); (ii) biodegradation (Martinez, 2009; Jechalke et al., 2014), or (iii) persistence unchanged in the effluent (Martinez, 2009; Wu et al., 2014). The dissemination of antibiotics, antibiotic residues, as well as ARGs and ARB excreted via food animal waste, leads to "environmental pollution" and therefore, establishes the environment as an important reservoir for the emergence and spread of AMR across the farmto-plate continuum (da Costa et al., 2013; Zhu et al., 2013; Wu et al., 2014; Woolhouse et al., 2015; Thanner et al., 2016).

In fact, the aquatic environment can serve both as natural AMR reservoir and route for the entrance in the food chain since aquatic bodies such as rivers, lakes, streams, and even coastlines, are generally endpoints receiving effluents from WWTPs and agricultural runoff, and increasing thereby the level of ARB and ARGs in natural ecosystems (Thanner et al., 2016; Williams et al., 2016; Suzuki et al., 2017). A critical review by Williams et al. (2016) highlighted oceans as the largest reservoir of ARGs in the environment, with $28 \%$ of known genes including clinically relevant and unknown genes (Williams et al., 2016). The authors also reported that the incidence of tetracycline resistance was twice as high in coastal runoff compared to forested area runoff as well as around $35 \%$ of beta-lactam ARGs (blaTEM-1+SHV12 and blactX-M-15) in environmental 
Enterobacteriales. This poses a serious public health risk as accidental ingestion of ARB-or ARGcontaining water may occur during bathing or recreational activities (Williams et al., 2016). Considering that 1.8 billion people, especially in developing countries, do not have access to safe drinking water, the high rate of ARGs reported in water surfaces could drastically increase morbidity and mortality due to resistant waterborne bacteria (RE-Act, 2014).

In addition, ARB and ARGs spread off a large livestock operation, termed confined animal feeding operation (CAFO), by several routes including via manure applied to land as fertilizer, from lorry transporting animals, wind leaving farm/abattoir facilities or even via flies or beetles attracted to the dung which can pick up and spread ARB. A recent study of the South Platte River in US, found that ARGs coding for resistance to sulphonamides were 10000 times superior in river sediments downstream compared to those upstream from larger feedlots (ones with 10000 cattle). The same study further revealed that these same ARGs were 1000 times higher from sewage treatment plants releasing ten million gallons of effluent per day compared to pristine sediments (Storteboom et al., 2010). Once these pollutants of animal origin escape the farm, genetic exchanges of resistance mechanisms with other bacteria, even those that have never been exposed to antibiotics can ensue. Consequently, farm soils, manure, waste streams and WWTPs have been acknowledged as "hot spots" of antibiotic pollution and dissemination of AMR in the food chain, with antibiotic residues, mobiles genetic elements (MGEs), ARGs, and ARB being detected across the world in these ecological niches (Zhu et al., 2013; Wu et al., 2014; Thanner et al., 2016). Horizontal gene transfer (HGT) has then been documented in these niches as well as in rivers, lakes and wildlife animals, and are involved in microbial communities containing various levels of ARB and ARGs (Zhu et al., 2013; Berendonk et al., 2015; Holmes et al., 2016; Thanner et al., 2016; von Wintersdorff et al., 2016).

How the environmental pollution contributes to the selection of resistant bacteria and the exacerbation of the environmental resistome (assortment of genes that are able to confer antibiotic resistance when expressed in a susceptible organism) elements is highlighted by a study from Huang et al. (2015) on 4767 commensal isolates originating from fish, feed and water of an aquaculture farm, which revealed that up to $80 \%$ were resistant to antibiotics with feed showing the highest levels upon real-time or quantitative PCR (qPCR) (Huang et al., 2015). Similarly, using qPCR arrays, Agga et al. (2015) detected 84 different ARGs from samples collected from four environments including municipal wastewater, low impact environment, cattle catchment ponds and swine waste lagoons. The study revealed that level of erythromycin-resistant enterococci was significantly higher in swine waste lagoons and cattle feedlot runoff compared to municipal wastewater and low impact environment (Agga et al., 2015). The authors further showed that concentration of trimethoprim-sulfamethoxazole-resistant $E$. coli were significantly higher in swine liquid than municipal liquid waste samples (Agga et al., 2015).

The dissemination of these materials onto soil increases AMR emergence and dissemination risks to (i) (wild) animals; (ii) crops, vegetables and fruits, (iii) surrounding water surfaces and groundwater; (iv) farm workers; and (vi) air and dust particles. Azanu et al. (2016) reported that carrot and lettuce, two vegetables that are frequently eaten raws, were associated with subinhibitory concentration of antibiotics (tetracycline and amoxicillin) upon water irrigation (Azanu et al., 2016). When recognizing that around $70 \%$ of global freshwater of agricultural production is based on resources from rivers, lakes and groundwater and are required to produce $20 \%$ of global foods (Keating et al., 2014), it is likely that ARB and ARGs spread to food animals and products, 
fish, shellfish, vegetables and water to ultimately reach the consumers and thereby, enhancing the public health risks associated with the presence of AMR in the farm-to-plate continuum (Acar and Moulin, 2006; Zhu et al., 2013; Thanner et al., 2016; Suzuki et al., 2017).

Besides, animal waste is used throughout the world and particularly in developing countries as fertilizer in crop lands, and, feeding of fish and shellfish in aquaculture. The persistence and changes in the resistome (Dantas and Sommer, 2012) of sludge or manure after anaerobic digestion or composting gained high interest worldwide and land spread of composted sludge has been associated with spread of ARGs in the soil and wider environment (Burkholder et al., 2006; Chen et al., 2011; Wei et al., 2011;Dantas and Sommer, 2012; Shah et al., 2012; Zhu et al., 2013; Wu et al., 2014; Khaliq et al., 2017). In keeping with this, Calero-Cáceres et al. (2014) reported an elevated prevalence of ARGs after digestion of sludge and suggested that agricultural use of sludge-harbouring ARB could significantly contribute to the spread of AMR in the environment (Calero-Cáceres et al., 2014). In addition, Xiao et al. (2016) used the structured Antibiotic Resistance Genes Database and metagenomic analyses to investigate and quantify ARGs in paddy soils from South China (Xiao et al., 2016). They identified 16 types of ARGs corresponding to 110 ARGs subtypes encompassing major resistance mechanisms and with multi-drug resistant genes (e.g. genes encoding efflux) being the most common type detected (range 38-47.5\%) in all samples (Xiao et al., 2016). Likewise, another report illustrated that the relative abundance of ARGs in samples collected from Chinese fish ponds used in aquaculture was as high as $2.8 \times 10^{-2}$ (Williams et al., 2016). Udiko-kolic et al., (2014) recently reported that application of manure as fertilizer to agricultural soil lead to emergence and dissemination of AMR, even when the animals that produced the manure were not treated with antibiotics (Udikovic-Kolic et al., 2014). The authors further concluded that enrichment of resident soil bacteria harbouring AMR elements is favoured by manure fertilization (Udikovic-Kolic et al., 2014). All this confirms that farm environments, especially soil and water may contribute to the spread of AMR along the farm-toplate continuum.

The environmental pollution is of particular concern as ARB and ARGs may spread through plant, crop production and wildlife, and revert back to animals and humans thereby increasing the risk of transmission of foodborne infections and pose food safety and public health risks, particularly in developing countries due to the limited access to clean water and precarious sanitary conditions. However, the impact of environmental pollution goes beyond selecting resistant mutants, favoring the acquisition of ARGs via HGT and food safety and public health threats, to the enrichment of the pool of intrinsically resistant microorganisms and reduction of susceptible ones in the environmental microbiota (Martinez, 2009). Cyanobacteria for instance, that are responsible of more than one third of $\mathrm{CO} 2$ fixation and total free $\mathrm{O} 2$ production are naturally susceptible to antibiotics, and there is currently no evidence that this population is suffering the impact of antibiotic pollution. However, the elimination of Cyanobacteria as a result of this pollution, might imbalance the micro-biosphere and have impact on climate change (Martinez, 2009). The AMR environmental pollution thereby threatens achievement of SDGs 2,3, 6, 12 and 15 promoting end of hunger, healthy lives and well-being, availability and sustainable management of water and sanitation for all, sustainable consumption and production as well as sustainable use of terrestrial ecosystem, respectively. It also endangers global actions undertaken in the mitigation of climate change.

\section{Climate change}


Food animal production and its environmental footprints is recognized as great contributor to climate change (Schipanski and Bennett, 2012; Gerber et al., 2013; Smith et al., 2013; Keating et al., 2014; Herrero et al., 2016; FAO, 2013, 2017). Indeed, after fossil fuels, animal agriculture is the second largest contributor of human made greenhouse gas (GHG) with deforestation, water and air pollution, and biodiversity losses being the main consequences (Schipanski and Bennett, 2012; Gerber et al., 2013; Herrero et al., 2016). A heavy strain on Earth's finite resources such as water, land and energy, is caused by animal agriculture in order to accommodate the world's 70 billion animals annually raised to feed the human population. As such, around $60 \%$ of global freshwater and a third of the planet's ice-free land and global grain production are dedicated to growing of food animals (Schipanski and Bennett, 2012; Gerber et al., 2013).

With the world's population projected to reach 9.7 billion by 2050 (UN DESA, 2015), the FAO estimates that the demand of animal proteins and crops, both through population growth and economic development, will require as much as a doubling the global food and agriculture production over the same time period (FAO, 2009, 2017). The consumption of meat and dairy products is projected to rise by 76 and $64 \%$ respectively, thereby, increasing the resource load from the food production industry (FAO, 2009,2017; Smith et al., 2013; Keating et al., 2014; Tilman and Clark, 2014).

The production and distribution of quality, nutritious and safe food for the expected 9 billion population by 2050, without destroying Earth's finite resources, including antimicrobial substances, represent a multifaceted challenge that lacks a single solution (Godfray et al., 2010; Tilman et al., 2011). The environmental repercussions of agricultural industrialization/expansion increases with the global food demand and this has been confirmed by a recent modelling study which revealed that meeting the unprecedented global demand on animal proteins relies on the agricultural evolution. If greater agricultural industrialization continues, around 1 billion ha of land would be cleared globally by 2050, with concentration of greenhouse gas (GHG) emissions reaching $\sim 3 \mathrm{Gt}^{-1}$ and azote use $\sim 250 \mathrm{Mt} \mathrm{y}^{-1}$ by the same year (Tilman et al., 2011).

As one of the foremost users of natural resources and thereby contributor to climate change, the food animal production sector needs to address its environmental footprints (Schipanski and Bennett, 2012; Gerber et al., 2013; Herrero et al., 2016). The sector currently faces the significant challenge to reduce its GHG emissions with the large part being caused by methane released from enteric fermentation and partly from animal manure (Schipanski and Bennett, 2012; Gerber et al., 2013), while responding to a substantial demand for animal and crop proteins (Tilman et al., 2011). This situation led farmers and food producers to favour and implement intensive agricultural practices that are over-reliant on antimicrobial medicines (Van Boeckel et al., 2015) that, besides threatening human, animal and environmental health with the emergence of ARB and ARGs, further exacerbates climate change and undermines the considerable efforts undertaken to combat it as depicted in SDGs 13 and 15 (UN, 2015).

Unsustainable food production and consumption practices were already recognized as reasons behind prolonged global environment deterioration in 1996 (FAO, 1996b). As food safety is intricately linked to sustainable consumption and production (Godfray et al., 2010; Smith et al., 2013; FAO, 1996a,b, 2015), AMR in the food chain may cause an imbalance leading to environmental issues and jeopardizing achievement of UN's SDGs 12 and 13 (UN, 2015). This is confirmed by a recent study of Hammer et al., (2016) which revealed that antimicrobial use in food animals increase GHG emissions from cow dung (Hammer et al., 2016). The authors showed that 
antibiotics, especially tetracycline used in this study, boost methane production in cowpats by favouring ARB and methane-producing organisms in the digestive systems (Hammer et al., 2016). The authors proposed that antibiotics do this by suppressing specific bacteria in the gut and dung that compete with the methane-producing ones, allowing methanogens to outcompete bacteria for hydrogen and thereby increasing concomitantly their methane output (Hammer et al., 2016). They reported that manure of cattle feed with tetracycline produced 1.8 times more methane, a potent and principal global warming gas, than normal manure, while their belches produced far more methane than their manure did (Hammer et al., 2016). The study further revealed that antibiotics changed the bacteria in the gut of dung beetles which are essential for cycling carbon and improving soil by reducing methane-producing effects of cow manure (Hammer et al., 2016). The challenges of increased food production are magnified by its potential impact on environmental sustainability and resource availability, which will require entirely new approaches, public-private collaboration, scientific discovery, and translation of results into effective strategies and policies for decision-makers (Tilman et al., 2011; Tilman and Clark, 2014; Travis et al., 2014).

\section{Global strategy to ensure food safety and sustainable development}

AMR in the food chain is a silent pandemic threat requiring holistic actions and sustainable political will and commitment. The manifold repercussions of AMR in the food chain extend beyond reduced productivity, benefits or health risks, and food safety to reach food insecurity, higher healthcare costs, drain on national and global economies as well as worsening climate change (FAO, 2015; Table 1 and Figure 2). Tackling AMR globally requires better use of antimicrobial substances in food production while substantially preventing and monitoring the transmission of resistance already present in the farm-to-plate continuum as containing it throughout this continuum will substantially lessen multi-sectorial implications associated with this issue. Interdependent and inter-related problems such as AMR need integrated and global solutions (Laxminarayan et al., 2016) as per the examples of Denmark (DANMAP, 2014), Sweden (Swedres-Svarm, 2015), and Norway (NORM and NORM-VET, 2015) where levels of antibiotic use and resistance are the lowest in the world, a situation partly due to the effective containment of AMR concomitantly in humans and animals. As with threats posed by the climate change, where positive results of interventions are already evident, sustainable efforts endorsed, coordinated and monitored by the United Nations in line with One Health approach, and involving WHO, FAO, OIE, UN Environment Programme (UNEP); the UN Children's Fund (UNICEF), UN Development Program (UNDP), UN Educational, Scientific and Cultural Organization (UNESCO), the World Bank and other multilateral agencies should be implemented to contain AMR from farm-to-plate, as part of a global coordinated plan (Laxminarayan et al., 2016).

Assessing the real implications of AMR is difficult, with the main reason being the impact of underlying ramifications that are not always well considered. In light of this, the farm-to-plate continuum that encompasses numerous ecological niches and where genetic exchanges prevail, need to be integrally considered when addressing the effective containment of AMR, conservation of antimicrobials for current and future generations, as well as sustainable development by 2030 . Multi-sectoral coordination is indispensable to preserve antimicrobial effectiveness for future generations and ensure sustainable animal and human healthcare systems as advances made in combating AMR through healthcare policies and interventions might be undermined by ARB and ARGs prevailing in the ecological niches of the farm-to-plate continuum (Bengtsson and Greko, 2014; Årdal et al., 2016). 


\section{ONE HEALTH}
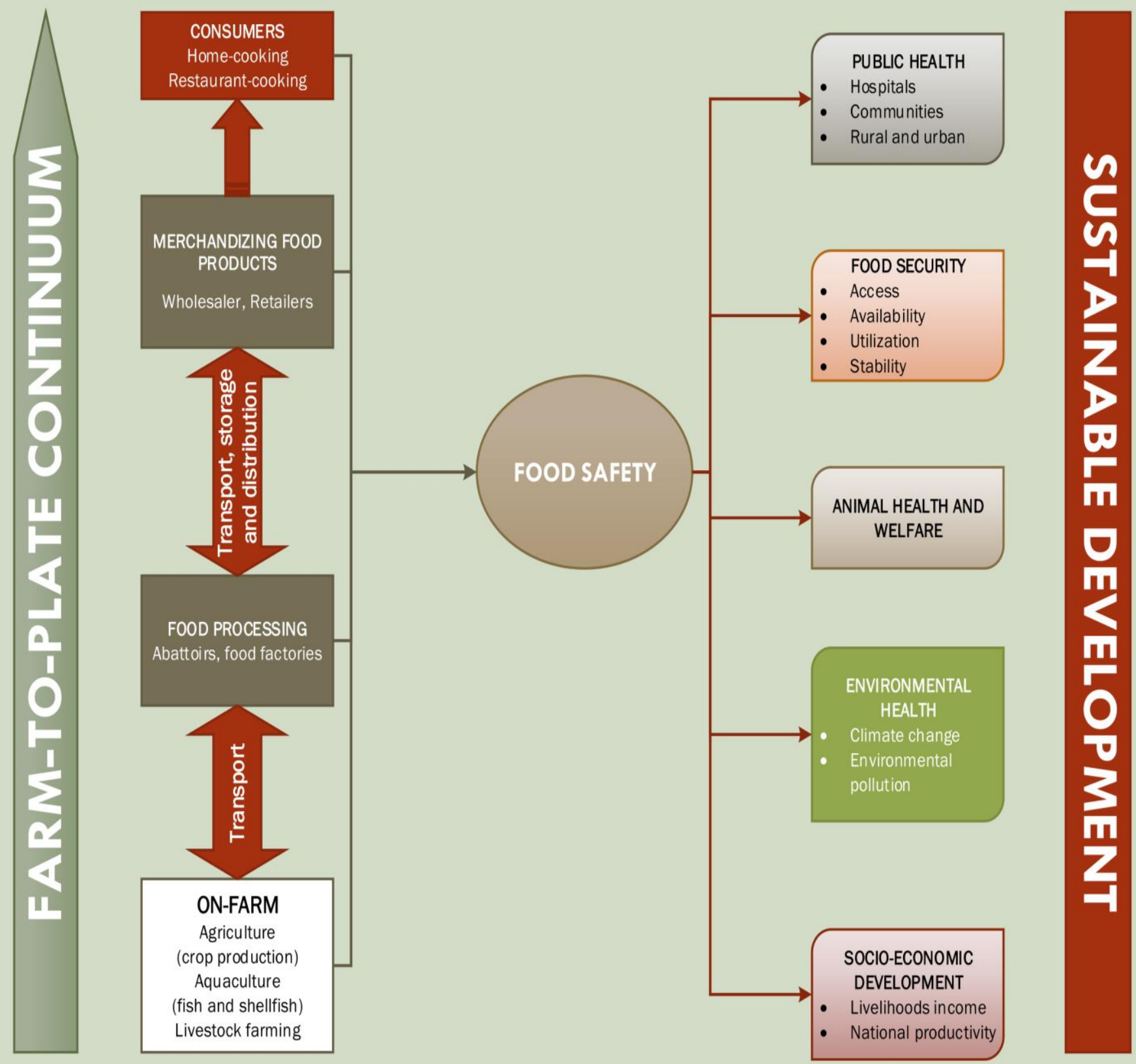

Figure 2. Emergence and spread of antimicrobial resistance in the farm-to-plate continuum and impact of food safety issues in the achievement of SDGs 
Table.1 Summary of implications of Antimicrobial resistance in the farm-to-plate continuum

\begin{tabular}{|c|c|c|c|}
\hline Implications of AMR & Direct impacts & Indirect impacts & SDGs affected \\
\hline Food security & $\begin{array}{c}\text { Unsafe food } \\
\text { Increased hunger and malnourishment }\end{array}$ & $\begin{array}{l}\text { Increased morbidity and mortality } \\
\text { Increased poverty }\end{array}$ & $\mathrm{SDG}^{\dagger} 1,2,3$ and 12 \\
\hline $\begin{array}{l}\text { Animal health and } \\
\text { welfare }\end{array}$ & $\begin{array}{c}\text { Therapeutic failure } \\
\text { Increased animal morbidity and mortality } \\
\text { Threat to animal well-being }\end{array}$ & $\begin{array}{l}\text { Increased cost of food production } \\
\text { Increased hunger } \\
\text { Endangered human health }\end{array}$ & SDG 1, 2, 3 and 12 \\
\hline Public health & $\begin{array}{c}\text { Intestinal and extra-intestinal foodborne } \\
\text { illness }\end{array}$ & $\begin{array}{c}\text { Endangered IPC } ₫ / A S P \\
\text { Increased cost of hospitalization and medication. }\end{array}$ & SDG 1 and 3 \\
\hline $\begin{array}{l}\text { Environmental } \\
\text { health }\end{array}$ & $\begin{array}{c}\text { Environmental pollution } \\
\text { Unsafe water } \\
\text { Change of environmental microbiome }\end{array}$ & $\begin{array}{l}\text { Increased hunger } \\
\text { Threatened sustainable consumption and production } \\
\text { Endangered sustainability of Earth's finite resource } \\
\text { Endangered human and animal health }\end{array}$ & SDG $2,3,6,12,15$ \\
\hline Climate change & $\begin{array}{l}\text { Increased greenhouse gas }(\mathrm{GHG}) \\
\text { emissions } \\
\text { Deterioration of natural resources }\end{array}$ & $\begin{array}{l}\text { Endangered public health, food security and climate } \\
\text { change actions }\end{array}$ & SDG $2,3,6,12,13,15$ \\
\hline $\begin{array}{l}\text { Socio-economic } \\
\text { development }\end{array}$ & $\begin{array}{l}\text { Increased poverty } \\
\text { Drain on national economy }\end{array}$ & $\begin{array}{c}\text { Increased hunger } \\
\text { Threatened education and well-being } \\
\text { Endangered policies and actions on sustainability }\end{array}$ & $\begin{array}{c}\text { SDG } 1,2,3,4,6,8 \\
12\end{array}$ \\
\hline
\end{tabular}

\footnotetext{
${ }^{\dagger}$ sustainable development goals

* infection, prevention and control

$\S$ Antimicrobial stewardship programs
} 
A multi-pronged strategy has been proposed to ensure food safety as it is a collective responsibility requiring collaboration among the government, food-producing industries and the public across the farm-to-plate continuum (viz. from farmers and food manufacturers to food-handlers and end consumers). Decision-makers should acknowledge food safety a public health priority, to ensure that all stakeholders along the whole farm-to-plate continuum, from the food producers and suppliers to the consumers, operate responsibly to preserve the safety of food while ensuring food security (WHO, 2015; Founou et al., 2016). Farmers should for instance be advised to implement effective biosecurity measures to prevent emergence of AMR and on-farm contamination with ARB and ARGs or external dissemination when contamination occurs, whereas food-handlers and consumers are advised to make use of WHO's tool "Five Keys to Safer Food" when cooking (WHO, 2015; Founou et al., 2016). Decision-makers should implement and maintain adequate and sustainable food systems and infrastructures in order to manage appropriately food safety risks throughout the entire farm-to-plate continuum. They should also foster multi-sectoral collaboration among animal, human and environmental health, agriculture and other sectors as well as systematically integrate food safety including containment of AMR in the farm-to-plate continuum, into all policies and interventions addressing better nutrition and food security. Governments should thus develop strategies and promote activities that contribute to ensure food safety, thereby global health and sustainable development.

Containing AMR requires a global approach combining multifaceted and comprehensive actions within the One Health approach, with a strong overarching goal to ensure food safety, sustain food security, combat communicable and non-communicable diseases successfully, as well as preserve antimicrobial effectiveness for future generations (FAO, 2015; O'Neill, 2015; WHO, 2015). Implementing the One Health approach is essential as sustainable healthcare solutions for current and future generations cannot be achieved in isolation but require well-coordinated efforts locally, nationally, regionally and internationally. The development of specific and achievable goals, reinforcement of political will, mobilization and allocation of resources, financial support to reinvigorate antibiotic pipeline and alternatives to antibiotics, and agreement on a responsible mechanism for global collective action on this threat are further required (Laxminarayan et al., 2016).

\section{Conclusion and key recommendations}

The emergence and spread of AMR in the farm-to-plate continuum is a food safety issue with public health implications just being the tip of the iceberg. Not considered, are the manifold implications on food security, animal health and welfare, socio-economic development, environment and climate change, which make the emergence and spread of AMR in this continuum amongst the keystones of this global disaster. In this regard, emergence and spread of AMR in the farm-to-plate continuum should not merely be considered a food safety issue but recognized as a grave barrier in the accomplishment of UN's SDGs. Policy makers and governments should invest smartly in food safety, heighten awareness to engage effectively with all stakeholder especially consumers and implement appropriate preventive measures in the farm-to-plate continuum.

\section{Funding}

This work was supported by the National Research Foundation [Grant No. 85595; 106063; and 98342]. The funders had no role in the study design, nor the decision to submit the work for publication.

\section{Author contributions}

LF co-conceptualized the study, co-conceived the review outline, searched, extracted and collated data, and drafted the manuscript. RF extracted and collated data and provided significant inputs to 
several sections to improve clarity and accuracy. SE co-conceptualized the study, co-conceived the review outline, and undertook a critical revision of the manuscript. All authors read and approved the final manuscript.

\section{References}

Acar, J. F., and Moulin, G. (2006). Antimicrobial resistance at farm level. Rev Sci Tech Off Int Epiz, 25(2), 775-792.

Adelowo, O. O., Fagade, O. E., and Agerso, Y. (2014). Antibiotic resistance and resistance genes in Escherichia coli from poultry farms, southwest Nigeria. J Infect Dev Ctries, 8(9), 11031112. doi: $10.3855 /$ jidc. 4222

Agga, G. E., Arthur, T. M., Durso, L. M., Harhay, D. M., and Schmidt, J. W. (2015). Antimicrobial-Resistant Bacterial Populations and Antimicrobial Resistance Genes Obtained from Environments Impacted by Livestock and Municipal Waste. Plos One, 10(7), e0132586. doi:10.1371/journal.pone.0132586

Aidara-Kane, A., Andremont, A., and Collignon, P. (2013). Antimicrobial resistance in the food chain and the AGISAR initiative. J Infect Public Health, 6, 162-165. doi:http://dx.doi.org/10.1016/j.jiph.2013.04.001

Ajayi, O. A., and Salaudeen, T. (2014). Consumer food safety awareness and knowledge in Nigeria. Int J Food Safety, 16, 17-24.

Ao, T. T., Feasey, N. A., Gordon, M. A., Keddy, K. H., Angulo, F. J., and Crump, J. A. (2015). Global Burden of Invasive Nontyphoidal Salmonella Disease, 2010. Emerg Infect Dis, 21(6), 941-949. doi:https://dx.doi.org/10.3201/eid2106.140999.

Årdal, C., Outterson, K., Hoffman, S.J., Ghafur, A., Sharland, M., Ranganathan, N., et al. (2016). International cooperation to improve access to and sustain effectiveness of antimicrobials. Lancet, 387, 296-307. doi:org/10.1016/S0140-6736(15)00470-5

Armand-Lefevre, L., Ruimy, R., and Andremont, A. (2005). Clonal Comparison of Staphylococcus aureus Isolates from Healthy Pig Farmers, Human Controls, and Pigs. Emerg Infect Dis, 11(5), 711-714. doi:10.3201/eid1105.040866

Azanu, D., Mortey, C., Darko, G., Weisser, J. J., Styrishave, B., and Abaidoo, R. C. (2016). Uptake of antibiotics from irrigation water by plants. Chemosphere, 157, 107-114.

Ben Sallem, R., Ben Slama, K., Rojo-Bezares, B., Porres-Osante, N., Jouini, A., Klibi, N., et al. (2014). IncI1 plasmids carrying bla(CTX-M-1) or bla(CMY-2) genes in Escherichia coli from healthy humans and animals in Tunisia. Microb Drug Resist, 20(5), 495-500. doi:10.1089/mdr.2013.0224

Bengtsson, B., and Greko, C. (2014). Antibiotic resistance-consequences for animal health, welfare, and food production. Uppsala J Med Sci, 119, 96-102.

Berendonk, T. U., Manaia, C. M., Merlin, C., Fatta-Kassinos, D., Cytryn, E., Walsh, F., et al. (2015). Tackling antibiotic resistance: the environmental framework. Nature Rev Microbiol, 13, 310-317.

Berendsen, B. J., Wegh, R. S., Memelink, J., Zuidema, T., and Stolker, L. A. (2015). The analysis of animal faeces as a tool to monitor antibiotic usage. Talanta, 132, 258-268. doi:10.1016/j.talanta.2014.09.022

Boonyasiri, A., Tangkoskul, T., Seenama, C., Saiyarin, J., Tiengrim, S., and Thamlikitku, V. (2014). Prevalence of antibiotic resistant bacteria in healthy adults, foods, food animals, and the environment in selected areas in Thailand. Pathog Global Health, 108(5), 235-245. 
Burkholder, J., Libra, B., Weyer, P., Heathcote, S., Kolpin, D., and Thorne, P. S. (2006). Impacts of waste from concentrated animal feeding operations on water quality. Environ Health Perspect, 115. doi:10.1289/ehp.8839

Calero-Cáceres, W., Melgarejo, A., Colomer-Lluch, M., Stoll, C., Lucena, F., Jofre, J., and Muniesa, M. (2014). Sludge as a Potential Important Source of Antibiotic Resistance Genes in Both the Bacterial and Bacteriophage Fractions. Environ Sci Technol, 48(13), 76027611. doi:10.1021/es501851s

Carlet, J. (2012). The gut is the epicentre of antibiotic resistance. Antimicrob Resistance Infect Control, 1(39). doi:10.1186/2047-2994-1-39

Chairat, S., Gharsa, H., Lozano, C., Gomez-Sanz, E., Gomez, P., Zarazaga, M., et al. (2015). Characterization of Staphylococcus aureus from Raw Meat Samples in Tunisia: Detection of Clonal Lineage ST398 from the African Continent. Foodborne Pathog Dis, 12(8), 686692. doi:10.1089/fpd.2015.1958

Chang, Q., Wang, W., Regev-Yochay, G., Lipsitch, M., and Hanage, W. P. (2015). Antibiotics in agriculture and the risk to human health: how worried should we be? Evol Appl, 8, 240245.

Chen, B., Zheng, W., Yu, Y., Huang, W., Zheng, S., Zhang, Y., et al. (2011). Class 1 integrons, selected virulence genes, and antibiotic resistance in Escherichia coli isolates from the Minjiang River, Fujian Province, China. Appl Environ Microbiol, 77(1), 148-155. doi:10.1128/aem.01676-10

Crombé, F., Argudín, M. A., Vanderhaeghen, W., Hermans, K., Haesebrouck, F., and Butaye, P. (2013). Transmission Dynamics of Methicillin-Resistant Staphylococcus aureus in Pigs. Front Microbiol, 4, 57. doi:10.3389/fmicb.2013.00057

da Costa, P. M., Loureiro, L., and Matos, A. J. F. (2013). Transfer of multi-drug resistant bacteria between intermingled ecological niches: the interface between humans, animals and the environment. Int J Environ Res Public Health, 10, 278-294. doi:10.3390/ijerph10010278

Dahms, C., Hübner, N.-O., Kossow, A., Mellmann, A., Dittmann, K., and Kramer, A. (2015). Occurrence of ESBL-Producing Escherichia coli in Livestock and Farm Workers in Mecklenburg-Western Pomerania, Germany. PLoS ONE, 10(11), e0143326. doi:10.1371/journal.pone.0143326

DANMAP. (2014). Use of antimicrobial agents and occurrence of antimicrobial resistance in bacteria from food animals, food and humans in Denmark. ISSN 1600-2032. Available from www.danmap.org. Accessed 2017 March 14.

Dantas, G., and Sommer, M. O. (2012). Context matters - the complex interplay between resistome genotypes and resistance phenotypes. Curr Opin Microbiol, 15(5), 577-582. doi:10.1016/j.mib.2012.07.004

de Balogh, K., Halliday, J., and Lubroth, J. (2013). Integrating the surveillance of animal health, foodborne pathogens and foodborne diseases in developing and in-transition countries. Rev Sci Tech Off Int Epiz, 32(2), 539-548.

Denkel, L. A., Gastmeier, P., and Leistner, R. (2016). The association of ESBL-producing Enterobacteriaceae (ESBL-E) carriage in humans with pigs. Epidemiol Infect, 144, 691692. doi:10.1017/S095026881500240X

Dohmen, W., Bonten, M. J. M., Bos, M. E. H., Marm, S. V., Scharringa, J., Wagenaar, J. A., and Heederik, D. J. J. (2015). Carriage of Extended-Spectrum Beta-lactamases in pig farmers is associated with occurence in pigs. Clin Microbiol Infect, 21 (10), 917-23. 
European Food Safety Authority (EFSA) and European Centre for Disease Prevention and Control (ECDC). (2015). The European Union summary report on trends and sources of zoonoses, zoonotic agents and food-borne outbreaks in 2013. EFSA Journal 2015; 13(1), 3991. doi:10.2903/j.efsa.2015.3991.

European Food Safety Authority (EFSA) and European Centre for Disease Prevention and Control (ECDC). (2016). The European Union summary report on antimicrobial resistance in zoonotic and indicator bacteria from humans, animals and food in 2014. EFSA J, 14(2), 4380.

Ewers C, Bethe A, Semmler T, Guenther S, and Wieler, L. H. (2012). Extended-spectrum blactamase-producing and AmpC-producing Escherichia coli from livestock and companion animals, and their putative impact on public health: a global perspective. Clin Microbiol Infect, 18, 646-655. doi:10.1111/j.1469-0691.2012.03850.x

FAO. (1996a). The state of food and agriculture. Rome: FAO.

FAO. (1996b). World Food Summit. Rome: FAO. Available from http://www.fao.org/wfs/index_en.htm

FAO. (2009). Global agriculture towards 2050. Rome: FAO.

FAO. (2013). FAO Statistical yearbook 2013: World Food and Agriculture. Rome: FAO. Available from http://www.fao.org/docrep/018/i3107e/i3107e00.htm. .

FAO. (2014). Rome Declaration on Nutrition. Rome: FAO.

FAO. (2015). Status Report on Antimicrobial Resistance. Rome: FAO.

Food and Agriculture Organization of the United Nations. 2016. The FAO Action Plan on

Antimicrobial Resistance 2016-2020. Rome: Food and Agriculture Organization of the United Nations.

FAO. (2016). Drivers, dynamics and epidemiology of antimicrobial resistance in animal production. Rome: FAO.

FAO. (2017). The future of food and agriculture. Rome: FAO.

Fashae, K., and Hendriksen, R. S. (2014). Diversity and antimicrobial susceptibility of Salmonella enterica serovars isolated from pig farms in Ibadan, Nigeria. Folia Microbiol (Praha), 59(1), 69-77. doi:10.1007/s12223-013-0270-6

Fortini, D., Fashae, K., Garcia-Fernandez, A., Villa, L., and Carattoli, A. (2011). Plasmid-mediated quinolone resistance and beta-lactamases in Escherichia coli from healthy animals from Nigeria. J Antimicrob Chemother, 66(6), 1269-1272. doi:10.1093/jac/dkr085

Founou, L. L., Founou, R. C., and Essack, S. Y. (2016). Antibiotic Resistance in the Food Chain: A Developing Country-Perspective. Front Microbiol, 7(1881). doi:10.3389/fmicb.2016.01881

Gerber, P. J., Steinfeld, H., Henderson, B., Mottet, A., Opio, C., Dijkman, J., Falcucci, A., Tempio, G. (2013). Tackling climate change through livestock - A global assessment of emissions and mitigation opportunities. Rome: FAO

Godfray, H. C. J., Beddington, J. R., Crute, I. R., Haddad, L., Lawrence, D., Muir, J. F., et al. (2010). Food Security: The Challenge of Feeding 9 Billion People. Science, 327, 812-818. doi:10.1126/science. 1185383

Hammer, T. J., Fierer, N., Hardwick, B., Simojoki, A., Slade, E., Taponen, J., et al. (2016). Treating cattle with antibiotics affects greenhouse gas emissions, and microbiota in dung and dung beetles. Proceed Royal Soc Lond B Biol Sci, 283(1831). doi:10.1098/rspb.2016.0150 
Herrero, M., Henderson, B., Havlik, P., Thornton, P. K., Conant, R. T., Smith, P., et al. (2016). Greenhouse gas mitigation potentials in the livestock sector. Nat Clim Change, 6, 452-460. doi:10.1038/NCLIMATE2925

Holmes, A. H., Moore, L. S. P., Sundsfjord, A., Steinbakk, M., Regmi, S., Karley, A., et al. (2016). Understanding the mechanisms and drivers of antimicrobial resistance. Lancet. doi:http://dx.doi.org/10.10.1016/S0140-6736(15)00473-0

World Economic Forum. (2013). The Global risks Report 2013. Geneva: World Economic Forum. Huang, Y., Zhang, L., Tiu, L., and Wang, H. H. (2015). Characterization of antibiotic resistance in commensal bacteria from an aquaculture ecosystem. Front Microbiol, 6, 914. doi:10.3389/fmicb.2015.00914

Iweriebor, B. C., Iwu, C. J., Obi, L. C., Nwodo, U. U., and Okoh, A. I. (2015). Multiple antibiotic resistances among Shiga toxin producing Escherichia coli O157 in feces of dairy cattle farms in Eastern Cape of South Africa. BMC Microbiol, 15. doi:10.1186/s12866-0150553-y

Smith, J., Sones, K., Grace, D., MacMillan, S., Tarawali, S. and Herrero, M. (2013). Beyond milk, meat, and eggs: Role of livestock in food and nutrition security. Animal Front, 3(1). doi:10.2527/af.2013-0002

Jaffee S, Henson S, Unnevehr L, Grace D, \& Cassou E. (2019). The Safe Food Imperative : Accelerating Progress in Low- and Middle-Income Countries. Washington, DC: World Bank.

Jahan, S. (2012). Epidemiology of Foodborne Illness In B. Valdez (Ed.), Scientific, Health and Social Aspects of the Food Industry. Rijeka: InTech.

Jakobsen, L., Hammerum, A. M., and Frimodt-Moller, N. (2010). Detection of clonal group A Escherichia coli isolates from broiler chickens, broiler chicken meat, community-dwelling humans, and urinary tract infection (UTI) patients and their virulence in mouse UTI model. Appl Environ Microbiol, 76, 8281-8284.

Jasovsky, D., Littmann, J., Zorzet, A., and Cars, O. (2016). Antimicrobial resistance- a threat to the world's sustainable development. Uppsala J Med Sciences, 121(3), 159-164.

Jechalke, S., Heuer, H., Siemens, J., Amelung, W., and Smalla, K. (2014). Fate and effects of veterinary antibiotics in soil. Trends Microbiol, 22(9), 536-545. doi:10.1016/j.tim.2014.05.005

Keating, B. A., Herrero, M., Carberry, P. S., Gardner, J., and Cole, M. B. (2014). Food wedges: Framing the global food demand and supply challenge towards 2050. Glob Food Sec. doi:http://dx.doi.org/10.1016/j.gfs.2014.08.004i

Khaliq, J. A., Mushtaque, A., Al-Wardy, M., Al-Busaidi, A., and Choudri, B. S. (2017). Wastewater and sludge management and research in Oman: An overview. J Air Waste Manage Assoc, 67(3), 267-278. doi:10.1080/10962247.2016.1243595

Kirk, M., Glass, K., Ford, L., Brown, K., Hall, G., National Centre For Epidemiology and Population Health, and Australian National University. (2014). Foodborne illness in Australia: Annual incidence circa 2010. Available from www.health.gov.au.

Klibi, N., Said, L. B., Jouini, A., Slama, K. B., Lopez, M., Sallem, R. B., et al. (2013). Species distribution, antibiotic resistance and virulence traits in enterococci from meat in Tunisia. Meat Sci, 93(3), 675-680. doi:10.1016/j.meatsci.2012.11.020

Kluytmans, J. A. J. W., Overdevest, I. T. M. A., Willemsen, I., Kluytmans-van den Bergh, M. F. Q., Zwaluw, K., and Heck, M. (2013). Extended-spectrum $\beta$-lactamase-producing 
Escherichia coli from retail chicken meat and humans: comparison of strains, plasmids, resistance genes, and virulence factors. Clin Infect Dis, 56. doi:10.1093/cid/cis929

Landers, T. F., Cohen, B., Wittum, T. E., and Larson, E. L. (2012). A Review of Antibiotic Use in Food Animals: Perspective, Policy, and Potential. Public Health Reports, 127.

Laxminarayan, R., Duse, A., Wattal, Zaidi, A. K. M., Wertheim, H. F. L., Sumpradit, N., et al. (2013). Antibiotic resistance-the need for global solutions. Lancet Infect Dis, 13(12), 1057-98. doi:http://dx.doi.org/10.1016/S1473-3099(13)70318-9

Laxminarayan, R., Amábile-Cuevas, C. F., Cars, O., Evans, T., D.L. Heymann, Hoffman, S., et al. (2016). UN High-Level Meeting on antimicrobials - what do we need?. The Lancet, 388(10041):218-220.

Leverstein-van Hall, M. A., Dierikx, C. M., Cohen Stuart, J., Voets, G. M., van den Munckhof, M. P., and van Essen-Zandbergen, A. (2011). Dutch patients, retail chicken meat and poultry share the same ESBL genes, plasmids and strains. Clin Microbiol Infect, 17(6), 873-880. doi:10.1111/j.1469-0691.2011.03497.x

Li, B., and Zhang, T. (2010). Biodegradation and adsorption of antibiotics in the activated sludge process. Environ Sci Technol, 44(9), 3468-3473. doi:10.1021/es903490h

Majowicz, S. E., Scallan, E., Jones-Bitton, A., Sargeant, J. M., Stapleton, J., Angulo, F. J., et al. (2014). Global Incidence of Human Shiga Toxin-Producing Escherichia coli Infections and Deaths: A Systematic Review and Knowledge Synthesis. Foodborne Pathog Dis, 11(6), 447-455. doi:10.1089/fpd.2013.1704

Manges, A. R., Smith, S. P., Lau, B. J., Nuval, C. J., Eisenberg, J. N., Dietrich, P. S., and al. (2007). Retail meat consumption and the acquisition of antimicrobial resistant Escherichia coli causing urinary tract infections: a case-control study. Foodborne Pathog Dis, 4, 419-431.

Marshall, B. M., and Levy, S. B. (2011). Food Animals and Antimicrobials: Impacts on Human Health. Clin Microbiol Rev, 24(4), 718-733. doi:doi:10.1128/CMR.00002-11

Martinez, J. L. (2009). Environmental pollution by antibiotics and by antibiotic resistance determinants. Env Pol, 157, 2893-2902. doi:10.1016/j.envpol.2009.05.051

Mensah, S. E., Koudande, O. D., Sanders, P., Laurentie, M., Mensah, G. A., and Abiola, F. A. (2014). Antimicrobial residues in foods of animal origin in Africa: public health risks. Rev Sci Tech, 33(3), 987-996, 975-986.

Newell, D. G., Koopmans, M., Verhoef, L., Duizer, E., Aidara-Kane, A., Sprong, H., et al. (2010). Food-borne diseases - the challenges of 20 years ago still persist while new ones continue to emerge. Int $\mathbf{J}$ Food Microbiol, 139 Suppl 1, S3-15. doi:10.1016/j.ijfoodmicro.2010.01.021

Nordstrom, L., Liu, C. M., and Price, L. B. (2013). Foodborne urinary tract infections: a new paradigm for antimicrobial resistant foodborne illness. Front Microbiol, 4(29). doi:10.3389/fmicb.2013.00029

NORM/NORM-VET (2015). Usage of Antimicrobial Agents and Occurrence of Antimicrobial Resistance in Norway. Tromsø/Oslo. ISSN: 1502-2307 (print) / 1890-9965 (electronic). Available at www.vetinst.no. Accessed 2016 July 15.

O'Neill, J. (2015a). Antimicrobials in agriculture and the environment: Reducing unnecessary use and waste. The Review on Antimicrobial Resistance.

O'Neill, J. (2015b). Tackling a global health crisis: initial steps. The Review on Antimicrobial Resistance.

O'Neill, J. (2016). Tackling Drug-Resistant Infections Globally: Final Report And Recommendations. The Review on Antimicrobial Resistance. 
OIE. (2016) The OIE Strategy on Antimicrobial Resistance and the Prudent Use of Antimicrobials. Paris: OIE

Ojo, O. E., Ajuwape, A. T. P., Otesile, E. B., Owoade, A. A., Oyekunle, M. A., and Adetosoye, A. I. (2010). Potentially zoonotic shiga toxin-producing Escherichia coli serogroups in the faeces and meat of food-producing animals in Ibadan, Nigeria. Int J Food Microbiol, 142(12), 214-221. doi:10.1016/j.ijfoodmicro.2010.06.030

Olatoye, I. O. (2010). The incidence and antibiotics susceptibility of Escherichia coli O157:H7 from beef in Ibadan Municipal, Nigeria. Afr J Biotechnol, 9(8), 1196-1199.

Padungtod, P., Kadohira, M., and Hill, G. (2008). Livestock Production and Foodborne Diseases from Food Animals in Thailand. J Vet Med Sci, 70(9), 873-879. doi:10.1292/jvms.70.873

Prabhakar, S. V. R. K., Sano, D., and Srivastava, N. (2010). Food safety in the Asia-Pacific Region: Current status, policy perspectives and a way forward Sustainable consumption and production in the Asia-Pacific region: Effective responses in a resource constrained world (Vol. White Paper III, pp. 215-298). Hayama, Japan: Institute for Global Environmental Strategies.

RE-Act. (2016). A fact sheet from ReAct - Action on Antibiotic Resistance. Available from www.reactgroup.org

Robinson, T. P., P.Bu, D., J. Carrique-Mas, E. M. Fèvre, M. Gilbert, D. Grace, et al. (2016). Antibiotic resistance is the quintessential One Health issue. Trans R Soc Trop Med Hyg, 110, 377-380. doi:10.1093/trstmh/trw048

Roess, A. A., Winch, P. J., Akhter, A., Afroz, D., Ali, N. A., Shah, R., et al. (2015). Household Animal and Human Medicine Use and Animal Husbandry Practices in Rural Bangladesh: Risk Factors for Emerging Zoonotic Disease and Antibiotic Resistance. Zoonoses Public Health, 62(7), 569-578. doi:10.1111/zph.12186

Rolain, J.-M. (2013). Food and human gut as reservoirs of transferable antibiotic resistance encoding genes. Front Microbiol, 4(173). doi:10.3389/fmicb.2013.00173

Sachs, J. D. (2012). From Millennium Development Goals to Sustainable Development Goals. Lancet, 379, 2206-2211.

Scharff, R. L. (2012). Economic burden from health losses due to foodborne illness in the United States. J Food Prot, 75(1), 123-131. doi:10.4315/0362-028x.jfp-11-058

Schipanski, M. E., and Bennett, E. M. (2012). The Influence of Agricultural Trade and Livestock Production on the Global Phosphorus Cycle. Ecosystems, 15(2), 256-268. doi:10.1007/s10021-011-9507-x

Shah, S. Q., Colquhoun, D. J., Nikuli, H. L., and Sorum, H. (2012). Prevalence of antibiotic resistance genes in the bacterial flora of integrated fish farming environments of Pakistan and Tanzania. Environ Sci Technol, 46(16), 8672-8679. doi:10.1021/es3018607

Singer, R. S. (2015). Urinary tract infections attributed to diverse ExPEC strains in food animals: evidence and data gaps. Front Microbiol, 6(28). doi:10.3389/fmicb.2015.00028

Smith, J., Sones, K., Grace, D., MacMillan, S., Tarawali, S., and Herrero, M. (2013). Beyond milk, meat, and eggs: Role of livestock in food and nutrition security. Animal Frontiers, 3(1), 613. doi:10.2527/af.2013-0002

Spellberg, B., Bartlett, J. G., and Gilbert, D. N. (2013). The Future of Antibiotics and Resistance. N Engl J Med, 368(4), 299-302. doi: 10.1056/NEJMp1215093

Storteboom, H., Arabi, M., Davis, J. G., Crimi, B., and Pruden, A. (2010). Tracking antibiotic resistance genes in the South Platte River basin using molecular signatures of urban, 
agricultural, and pristine sources. Environ Sci Technol, 44(19), 7397-7404. doi:10.1021/es101657s

Suzuki, S., Pruden, A., Virta, M., and Zhang, T. (2017). Editorial: Antibiotic resistance in aquatic systems. Front Microbiol, 8(14). doi: 10.3389/fmicb.2017.00014.

Swartz, M. N. (2002). Human Diseases Caused by Foodborne Pathogens of Animal Origin. Clin Infect Dis, 34, S111-S122.

Swedres-Svarm. (2015). Consumption of antibiotics and occurrence of antibiotic resistance in Sweden. Solna/Uppsala: Public Health Agency of Sweden and National Veterinary Institute.

Tack DM, Marder EP, \& Griffin PM. (2019). Preliminary Incidence and Trends of Infections with Pathogens Transmitted Commonly Through Food - Foodborne Diseases Active Surveillance Network, 10 U.S. Sites, 2015-2018. MMWR Morb Mortal Wkly Rep, 68, 369-373. doi:http://dx.doi.org/10.15585/mmwr.mm6816a2

Thanner, S., Drissner, D., and Walsh, F. (2016). Antimicrobial Resistance in Agriculture. MBio, 7(2), e02227-02215. doi:10.1128/mBio.02227-15.

Tilman, D., Balzer, C., Hill, J., and Befort, B. L. (2011). Global food demand and the sustainable intensification of agriculture. Proc Natl Acad Sci, 108(50), 20260-20264. doi:10.1073/pnas.1116437108

Tilman, D., and Clark, M. (2014). Global diets link environmental sustainability and human health. Nature, 515(7528), 518-522. doi:10.1038/nature13959 http://www.nature.com/nature/journal/v515/n7528/abs/nature13959.html\#supplementaryinformation

Tomson, G., and Vlad, I. (2014). The need to look at antibiotic resistance from a health systems perspective. Uppsala J Med Sci, 119, 117-124.

Travis, D. A., Sriramarao, P., Cardona, C., Steer, C. J., Kennedy, S., Sreevatsan, S., and Murtaugh, M. P. (2014). One Medicine One Science: a framework for exploring challenges at the intersection of animals, humans, and the environment. Ann N Y Acad Sci, 26-44. doi:10.1111/nyas.12601

Udikovic-Kolic, N., Wichmann, F., Broderick, N. A., and Handelsman, J. (2014). Bloom of resident antibiotic-resistant bacteria in soil following manure fertilization. Proc Natl Acad Sci U S A, 111(42), 15202-15207. doi:10.1073/pnas.1409836111

United Nations (UN). (2015). Transforming our world: The 2030 Agenda for Sustainable Development. New-York: United Nations.

United Nations (UN). (2017). Interagency Coordination Group on Antimicrobial Resistance. Available from https://www.un.org/sg/en/content/sg/personnel-appointments/2017-0317/interagency-coordination-group-antimicrobial-resistance. Last access 10 May 2017.

United Nations, Department of Economic and Social Affairs, Population Division (UN DESA). (2015). World Population Prospects: The 2015 Revision, Key Findings and Advance Tables. New-York: United Nations, Department of Economic and Social Affairs, Population Division (UN DESA).

Van Boeckel, T. P., Brower, C., Gilbert, M., Grenfell, B. T., Levin, S. A., Robinson, T. P., et al. (2015). Global trends in antimicrobial use in food animals. Proc Natl Acad Sci USA, 112(18), 5649-5654. doi:10.1073/pnas.1503141112

Van Loo, I., Huijsdens, X., Tiermersma, E., de Neeling, A., van de Sande-Bruinsma, N., Beaujean, D., et al. (2007). Emergence of Methicillin-Resistant Staphylococcus aureus of Animal Origin in Humans. Emerg Inf Dis, 13(12), 1834-1839. 
von Wintersdorff, C. J. H., Penders, J., van Niekerk, J. M., Mills, N. D., Majumder, S., van Alphen, L. B., et al. (2016). Dissemination of Antimicrobial Resistance in Microbial Ecosystems through Horizontal Gene Transfer. Front Microbiol, 7, 173. doi:10.3389/fmicb.2016.00173

Voss, A., Loeffen, F., Bakker, J., Klaassen, C., and Wulf, M. (2005). Methicillin-resistant Staphylococcus aureus in Pig Farming. Emerging Infectious Diseases, 11(12), 1965-1966. doi:10.3201/eid1112.050428

Ward, M. J., Gibbons, C. L., van Bunnik, B. A. D., Grirvan, E. K., Edwards, G. F., Fitzgerald, J. R., and Woolhouse, M. E. J. (2014). Time-scaled evolutionary analysis of the transmisison and antibiotic resistance dynamics of Staphylococcus aureus Clonal Complex 398. Appl Environ Microbiol, 80(23), 7275-7282.

Weese, J. S. (2010). Methicillin Resistant Staphylococcus aureus in animals. ILAR J, 51(3), 233 244.

Wei, R., Ge, F., Huang, S., Chen, M., and Wang, R. (2011). Occurrence of veterinary antibiotics in animal wastewater and surface water around farms in Jiangsu Province, China. Chemosphere, 82(10), 1408-1414. doi:10.1016/j.chemosphere.2010.11.067

World Health Organization (WHO). (2011). Tackling antibiotic resistance from a food safety perspective in Europe. Copenhagen: WHO Europe.

World Health Organization (WHO). (2013). Advancing food safety initiatives: Strategic plan for food safety including foodborne zoonoses. Geneva: WHO

World Health Organization (WHO). (2014). Antimicrobial resistance: global report on surveillance. Geneva: WHO

World Health Organization (WHO). (2015a). Global Action Plan on Antimicrobial Resistance. Geneva: WHO.

World Health Organization (WHO). (2015b). Food Safety-Fact Sheet N 399. Geneva:WHO.

World Health Organization (WHO). (2015c). WHO estimates of the global burden of foodborne diseases: foodborne disease burden epidemiology reference group 2007-2015. Geneva: WHO.

World Organization for Animal Health (OIE). 2015. List of antimicrobial agents of veterinary importance. Paris: World Organization for Animal Health.

World Organization for Animal Health (OIE). 2016. Terrestrial Animal Health Code. Paris: World Organization for Animal Health.

Williams, M. R., Stedtfeld, R. D., Guo, X., and Hashsham, S. A. (2016). Antimicrobial resistance in the environment. Water Environ Res, 88(10), 1951-1967. doi:10.2175/106143016X14696400495974

Wooldridge, M. ( 2012). Evidence for the circulation of antimicrobial- resistant strains and genes in nature and especially between humans and animals. Rev Sci Tech Off Int Epiz, 31(1), 231-247.

Woolhouse, M., Ward, M., van Bunnik, B., and Farrar, J. (2015). Antimicrobial resistance in humans, livestock and the wider environment. Phil Trans R Soc B, 370, 20140083. doi:dx.doi.org/10.1098/rstb.2014.0083

World Bank. (2016). Drug-Resistant Infections: A Threat to Our Economic Future (Discussion Draft) Washington, DC: World Bank.

Wu, X. L., Xiang, L., Yan, Q. Y., Jiang, Y. N., Li, Y. W., Huang, X. P., et al. (2014). Distribution and risk assessment of quinolone antibiotics in the soils from organic vegetable farms of a subtropical city, Southern China. Sci Total Environ, 487, 399-406. doi:10.1016/j.scitotenv.2014.04.015 
Xiao, K.-Q., Li, B., Ma, L., Bao, P., Zhou, X., Zhang, T., and Zhu, Y.-G. (2016). Metagenomic profiles of antibiotic resistance genes in paddy soils from South China. FEMS Microbiol Ecol, 92, fiw023. doi:10.1093/femsec/fiw023

Zhu, Y.-G., Johnson, T. A., Su, J.-Q., Qiao, M., Guo, G.-X., Stedtfeld, R. D., et al. (2013). Diverse and abundant antibiotic resistance genes in chinese swine farms. Proc Natl Acad Sci, 110(9), 3435-3440. doi:10.1073/pnas.1222743110 